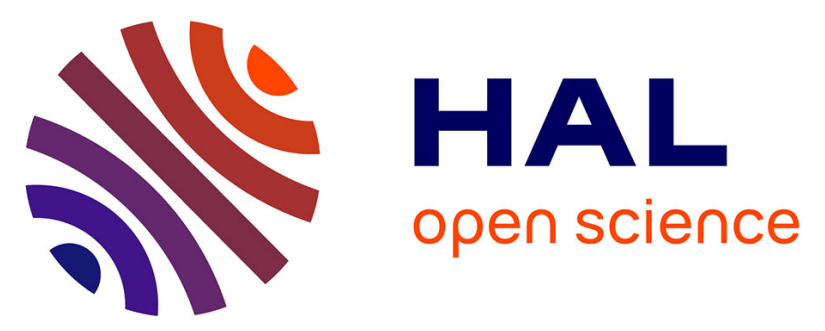

\title{
Identification of ion pairs in solution by IR spectroscopy: crucial contributions of gas phase data and simulations
}

Sana Habka, Thibaut Véry, Jeremy Donon, Vanesa Vaquero-Vara, Benjamin

Tardivel, Florence Charnay-Pouget, Michel Mons, David Aitken, Valérie

Brenner, Eric Gloaguen

\section{To cite this version:}

Sana Habka, Thibaut Véry, Jeremy Donon, Vanesa Vaquero-Vara, Benjamin Tardivel, et al.. Identification of ion pairs in solution by IR spectroscopy: crucial contributions of gas phase data and simulations. Physical Chemistry Chemical Physics, 2019, 21 (24), pp.12798-12805. 10.1039/c9cp00700h . cea-02160902

\section{HAL Id: cea-02160902 https://hal-cea.archives-ouvertes.fr/cea-02160902}

Submitted on 26 Nov 2020

HAL is a multi-disciplinary open access archive for the deposit and dissemination of scientific research documents, whether they are published or not. The documents may come from teaching and research institutions in France or abroad, or from public or private research centers.
L'archive ouverte pluridisciplinaire HAL, est destinée au dépôt et à la diffusion de documents scientifiques de niveau recherche, publiés ou non, émanant des établissements d'enseignement et de recherche français ou étrangers, des laboratoires publics ou privés. 


\title{
Identification of ion pairs in solution by IR spectroscopy: crucial contributions of gas phase data and simulations
}

Received 00th January 20xx, Accepted 00th January 20xx DOI: $10.1039 / \times 0 \times x 00000 x$

www.rsc.org/

\author{
Sana Habka, ${ }^{\mathrm{a},{ }^{\dagger}}$ Thibaut Very, ${ }^{\mathrm{a},{ }^{+\dagger}}$ Jeremy Donon, ${ }^{\mathrm{a}}$ Vanesa Vaquero-Vara, ${ }^{\mathrm{a}}$ Benjamin Tardivel, ${ }^{\mathrm{a}}$ \\ Florence Charnay-Pouget, ${ }^{\mathrm{b}}$ Michel Mons, ${ }^{\mathrm{a}}$ David J. Aitken, ${ }^{\mathrm{b}}$ Valérie Brenner ${ }^{\mathrm{a}}$ and Eric Gloaguen*a
}

In a context where structure elucidation of ion pairs in solution remains a contemporary challenge, this work explores an original approach where accurate gas phase spectroscopic data are used to refine high level quantum chemistry calculations of ion pairs in solution, resulting in an unprecedented level of accuracy in vibrational frequency prediction. First, gas phase studies focus on a series of isolated contact ion pairs ( $\mathrm{M}^{+}, \mathrm{Ph}_{-} \mathrm{CH}_{2}-\mathrm{COO}$, with $\mathrm{M}=\mathrm{Li}, \mathrm{Na}, \mathrm{K}, \mathrm{Rb}, \mathrm{Cs}$ ) for which conformer-selective IR spectra in the $\mathrm{CO}_{2}^{-}$stretch region are recorded. These experiments reveal the interactions at play in isolated contact ion pairs, and provide vibrational frequencies enabling us to assess the accuracy of the theoretical approach used, i.e., mode-dependent scaled harmonic frequency calculations at the RI-B97-D3/dhf-TZVPP level. This level of calculation is then employed on large water clusters embedding either a free acetate ion or its contact or solventshared pairs with a sodium cation in order to simulate the individual vibrational spectra of these species in solution. This study shows that the stretching modes of carboxylate are sensitive to both solvent-shared and contact ion pair formation. FTIR spectra of solutions of increasing concentrations indeed reveal several spectral changes consistent with the presence of specific types of solvent-shared and contact ion pairs. By providing relevant guidelines for the interpretation of solution phase IR spectra, this work illustrates the potential of the approach for the elucidation of supramolecular structures in electrolyte solutions.

\section{Introduction}

Characterisation of ion pairs in electrolyte solutions is a challenging task despite the existence of numerous analytical methods which are sensitive to ion pair formation. ${ }^{1,2}$ Most of these methods, including potentiometry or conductometry, suffer from the coexistence of different types of ion pairs in addition to free ions, i.e. contact (CIPS), solvent-shared (SIPS) and other solvent-separated ion pairs (SSIPs), each of them contributing to the total measured signal. In order to identify the respective contributions, the total signal often has to be decomposed using theoretical models that have their own limitations. At best, spectroscopic techniques may provide

\footnotetext{
a. LIDYL, CEA, CNRS, Université Paris Saclay; CEA Saclay, Bât 522, 91191 Gif-surYvette, France

b.ICMMO, CNRS, Université Paris Sud, Université Paris Saclay, UMR 8182, Bât. 420 15 rue Georges Clémenceau, 91405 Orsay cedex, France

+ present address: Biomolecular Mass Spectrometry and Proteomics, Utrecht University, Padualaan 8, $3584 \mathrm{CH}$ Utrecht, The Netherlands

†† present address: IDRIS-CNRS, Campus Universitaire d'Orsay, BP 167, 91403 Orsay cedex

Electronic Supplementary Information (ESI) available: S1 Gas phase DFT-D calculations; S2 AMOEBA parameters; S3 Conformational search at the AMOEBA force field level; S4 DFT-D calculations in solution; S5 Energy profile between O-O and $\mathrm{O}-\mathrm{O}-\pi$ conformers of $\left(\mathrm{M}^{+}, \mathrm{PA}^{-}\right)$systems; $\mathrm{S} 6$ Results used to determine modedependent scaling functions; S7 Mode-dependent scaled harmonic frequencies and splitting compared to gas phase experimental values; S8 Structural change from phenylacetic acid to $\left(\mathrm{Cs}^{+}, \mathrm{PA}\right)$; 59 Results of mode-dependent scaled harmonic frequency calculations in solution at the RI-B97-D3/dhf-TZVPP level. See DOI: $10.1039 / x 0 x x 00000 x$
}

direct evidence for the presence of ion pairs, which is often revealed by new spectral features beside those of the free ions identified at weak electrolyte concentrations. However, these techniques still generate data that require interpretation, which has already been shown to be counter-intuitive on several occasions. ${ }^{1}, 3$ In this context where the individual spectrum of each type of pair is required, theoretical chemistry is often invoked to provide invaluable reference values and assist with the assignment of spectral features. ${ }^{2,} 4$ This situation is typically encountered in vibrational spectroscopy where the help of quantum chemistry is widely appreciated. ${ }^{5,6}$ Unfortunately, comparison between bulk experimental spectra and frequency calculations at high quantum chemistry level is not straightforward and is indeed sometimes questionable (poor modelling of the environment around the vibrational probe, simplistic corrections of harmonic frequencies...). In response to the need of benchmark data for each type of ion pair, gas phase investigations have recently proven their ability to provide IR spectra of type-selected pairs by mass- and conformer-selective techniques. 7,8

While numerous charged ion pairs have been investigated in the gas phase, ${ }^{9-20}$ spectroscopic studies on neutral ion pairs other than alkali halide systems ${ }^{21,22}$ are rare in the literature. Following the pioneering work of Leone and co-workers in 2007,23 an ion pair from an ionic liquid was characterised by its IR spectrum in the gas phase, first by helium nanodroplet isolation spectroscopy, ${ }^{24}$ and by IR/UV double resonance spectroscopy. ${ }^{7}$ The fact that only a limited number of studies 
have been carried out is probably due to the difficulty of forming isolated ion pairs by thermal vaporisation, ${ }^{25}$ even though ionic liquids are among the easiest salts to vaporise, which underlines the challenge of such experiments. Recently, ${ }^{8}$ laser desorption combined with IR/UV spectroscopy was used to study alkali carboxylate salts, less volatile than ionic liquids, and characterise their CIPs by monitoring the $\mathrm{CO}_{2}^{-}$stretch spectral region, particularly sensitive to the type of pairing. ${ }^{26}$

Alkali acetates have been the focus of a number of recent studies seeking the characterisation of ion pair distribution in solution as a function of ion concentration. Indeed, the nature of pairing between alkali and carboxylate groups plays an essential role at the solvent-protein interface ${ }^{27,28}$ and is thought to contribute to the poorly understood counter-ion effects observed in the Hofmeister series. ${ }^{29}$ On the theoretical side, ion pair type distributions have been calculated at $1 \mathrm{M}$ using a force field specifically designed for electrolyte solutions. ${ }^{30}$ On the experimental side, dielectric relaxation spectroscopy ${ }^{31}, 32$ as well as Fourier-Transformed Infrared (FTIR) and Raman experiments 5,6 have detected signals assigned to SIPs, while X-ray absorption spectroscopy experiments in microjets ${ }^{33}, 34$ claim to have detected CIPs in the same concentration range.

In order to better understand these phenomena, we now endeavour to provide type-resolved vibrational spectra of ion pairs between a carboxylate anion and an alkali cation. An initial matter to accommodate is that isolated alkali acetate CIPs cannot be interrogated by the conformer-selective IR/UV double resonance technique due to the lack of a near-UV chromophore. This limitation is bypassed by studying alkali phenylacetates $\left(\mathrm{PA}^{-}\right)$where the phenyl ring serves as a chromophore. IR spectra of the isolated CIP series ( $\left.\mathrm{M}^{+}, \mathrm{PA}^{-}\right)$, where $\mathrm{M}=\mathrm{Li}, \mathrm{Na}, \mathrm{K}, \mathrm{Rb}$ or $\mathrm{Cs}$ (or $\mathrm{Li}-\mathrm{Cs}$ in short), are thus presented. Structural assignment is made by comparison with high level quantum chemistry calculations at the B97-D3 level, the reliability of which is also being assessed on these systems at the same time. This theoretical approach, improved by the comparison with gas phase measurements, is then applied to the acetate anion ( $\mathrm{AcO}^{-}$) and sodium acetate $\mathrm{CIPs}$ and SIPs solvated by at least two shells of explicit water molecules plus a solvent continuum model, giving an unprecedented description of the structure of these systems at the quantum chemistry level, together with their individual vibrational spectra. FTIR spectra in solution are thus interpreted in light of these new results.

\section{Methods}

\section{Gas phase spectroscopy}

Spectroscopy of isolated ion pairs was carried out using an experimental approach and setup described elsewhere. ${ }^{8,} 35$ Briefly, $\left(\mathrm{M}^{+}, \mathrm{PA}^{-}\right)$ion pairs were first vaporised by laser desorption of a solid sample comprised of a mixture of the desired salt with graphite, and then cooled down in a supersonic expansion of a 7:3 He:Ne gas mixture. Ion pairs were photo-ionised by a UV laser pulse following a resonant two-photon ionisation scheme (R2PI) where the wavelength was set to excite the first $\pi \pi^{*}$ state of the phenyl group. Conformer-selective IR spectra in the spectral region of the $\mathrm{CO}_{2}{ }^{-}$stretches were recorded using a IR/UV double resonance technique. ${ }^{36}$ For this purpose, an IR laser pulse was sent prior to the UV pulse tuned to specifically ionise one conformer: when the IR laser wavelength was resonant with a vibrational transition of this conformer, a depopulation of the vibrational ground state occurred, leading to a depletion of the ion signal. Conformer-selective IR spectra were thus obtained by monitoring this signal with a time-of-flight mass spectrometer while the wavelength of the IR laser was scanned.

\section{Theoretical analysis of isolated ion pairs}

A conformational search was performed for each $\left(\mathrm{M}^{+}, \mathrm{PA}^{-}\right)$ system: several structures with different positions of the cation around the carboxylate group were optimised at a dispersion-corrected density functional theory (DFT-D) level, 37 RI-B97-D3/dhf-TZVPP, ${ }^{38-40}$ using TURBOMOLE 7.0 (ESI, section S1). ${ }^{41}$ Harmonic vibrational frequencies were calculated at the same level. Additional single point calculations enabled us to obtain energies at the BSSE-corrected-full-CCSD(T)/dhfTZVPP//RI-B97-D3/dhf-TZVPP level. ${ }^{42,} 43$ These energies, combined with zero point energy and thermodynamic corrections calculated at the RI-B97-D3/dhf-TZVPP level were used to calculate Gibbs energies.

Optimisations and frequency calculations were carried out similarly on a set of previously investigated ${ }^{9-16}$ carboxylate- $^{-}$ containing systems in order to build mode-dependent scaling factors ${ }^{44-46}$ for the carboxylate symmetric and antisymmetric stretching modes, labelled $\left(\mathrm{CO}_{2}^{-}\right)^{\text {sym }}$ and $\left(\mathrm{CO}_{2}^{-}\right)^{\text {anti }}$ respectively.

\section{Theoretical spectra of ion pairs in solution}

The objective was to calculate vibrational spectra of each type of pair with enough accuracy to compare them with spectra recorded in solution. We thus designed an approach targeting a high level of theory applicable to the ions and their first two solvation shells in order to obtain accurate vibrational frequency calculations, although this level is not compatible with MD simulations. For this purpose, a two-step strategy was followed, whereby (i) the minima of the potential energy surface of explicitly hydrated ions were explored at the AMOEBA polarisable force field level ${ }^{47}$ using the TINKER software package, ${ }^{48}$ and (ii) a selection of representative structures were further optimised and their harmonic frequency calculated at the RI-B97-D3/dhf-TZVPP level. This strategy was applied to acetate and to sodium acetate ion pairs. The AMOEBA multipolar distribution for acetate was not available in the literature; it was therefore calculated (ESI, section $\mathrm{S2}$ ).

The systems considered in the first step were aggregates made of (i) a conformationally explored core containing the desired ion(s), acetate either alone or with a sodium cation, surrounded by at least two hydration shells around each ion, (ii) a $\sim 0.8 \mathrm{~nm}$-thick shell made of several hundreds of water molecules frozen in a AMOEBA minimum geometry (Fig. S1). This frozen shell ensured that the density remains fixed at 
1.016 , which is that of $\sim 0.4 \mathrm{M}$ sodium acetate solution. ${ }^{5}$ Exploration was conducted following a global method based on a biased Monte-Carlo minimisation algorithm developed by Scheraga ${ }^{49}$ implemented in TINKER (ESI, section S3).

From the minima found by the exploration, starting structures for geometry optimisations at the RI-B97-D3/dhf-TZVPP level were defined by extracting the ions and three hydration shells around them, i.e. typically a hundred water molecules. Optimisations were then carried out with a frozen outside shell, and with a solvent continuum model $\mathrm{COSMO}^{50}$ implemented in TURBOMOLE (Fig. S3). Harmonic vibrational frequency calculations were further carried out at the RI-B97D3/dhf-TZVPP level and restricted to the vibrational modes of the ions and the water molecules $\mathrm{H}$-bonded to the carboxylate group (ESI, section $\mathrm{S} 4$ ).

\section{Solution phase infrared spectra}

A stock solution (3.6 M) was made by dissolving sodium acetate trihydrate (4.923 g; Prolabo Normapur ${ }^{\circledR}$ grade) in pure water (PURIST, Rephile Bioscience) to give $10.0 \mathrm{~mL}$ of solution. This stock solution was used to prepare a set of sample solutions with concentrations of 3.6, 3.0, 2.4, 2.1, 1.8, 1.5, 1.2, $0.9,0.6,0.3$ and $0.15 \mathrm{M}$.

FTIR spectra were recorded on a Perkin-Elmer UATR Spectrum Two infrared spectrometer fitted with a synthetic diamond accessory using the attenuated total reflection (ATR) technique. An aliquot of each sample solution $(5 \mu \mathrm{L})$ was deposited on the ATR diamond for analysis. Pure water was used as the reference. Data were acquired in the wavenumber range between $1250 \mathrm{~cm}^{-1}$ and $1750 \mathrm{~cm}^{-1}$ with an analysis interval of $0.2 \mathrm{~cm}^{-1}$ and a spectral resolution of $4 \mathrm{~cm}^{-1}$.

\section{Isolated contact ion pairs}

According to the results published for $\left(\mathrm{Li}^{+}, \mathrm{PA}^{-}\right), 8$ the conformational landscape of $\left(\mathrm{M}^{+}, \mathrm{PA}^{-}\right)$is expected to be controlled by two main interactions, cation-anion and cation$\pi$. Indeed, three types of conformer were found at the DFT-D level (Fig. 1) and named according to the bond(s) between cations and anions: one or two " $\mathrm{O}$ " when $\mathrm{M}^{+}$binds to one or two oxygen atoms of carboxylate, respectively, and " $\pi$ " when $\mathrm{M}^{+}$binds to the aromatic ring. Conformer O-O is always the lowest in energy for all alkali cations (Table 1), whereas conformer $0-\pi$ is always found at sufficiently high energy $\left(>29 \mathrm{~kJ} \mathrm{~mol}^{-1}\right.$ ) to render its contribution negligible. Conformer $\mathrm{O}-\mathrm{O}-\pi$ was only found for $\mathrm{M}=\mathrm{K}-\mathrm{Cs}$, with low energies compatible with experimental observation $\left(<14 \mathrm{~kJ} \mathrm{~mol}^{-1}\right)$. However, calculations of the energy profile along the isomerisation path between conformers $\mathrm{O}-\mathrm{O}$ and $\mathrm{O}-\mathrm{O}-\pi$ at a higher level of theory (BSSE-corrected-full-CCSD(T)/dhf-TZVPP) suggest that $\mathrm{O}-\mathrm{O}-\pi$ is not a minimum (Fig. S4). Conformers $\mathrm{O}-\mathrm{O}$ are thus expected to be the only ones observed experimentally.

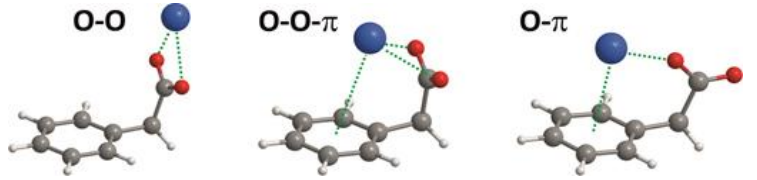

Figure 1. Three conformers of $\left(\mathrm{K}^{+}, \mathrm{PA}^{-}\right)$named according to the main non-covalent interactions (dashed lines) which characterise their structure.

\begin{tabular}{|c|c|c|c|}
\hline & Conformer & $\Delta \mathrm{G}(300 \mathrm{~K}) \mathrm{kJ} \mathrm{mol}^{-1}$ & $\Delta v\left(\mathrm{CO}_{2}^{-}\right) \mathrm{cm}^{-1}$ \\
\hline \multirow{2}{*}{$\left(\mathrm{Li}^{+}, \mathrm{PA}^{-}\right)$} & $\mathrm{O}-\mathrm{O}$ & 0 & 149 \\
\hline & $0-\pi$ & 44 & 536 \\
\hline \multirow{2}{*}{$\left(\mathrm{Na}^{+}, \mathrm{PA}^{-}\right)$} & $\mathrm{O}-\mathrm{O}$ & 0 & 196 \\
\hline & $0-\pi$ & 44 & 518 \\
\hline \multirow{3}{*}{$\left(\mathrm{K}^{+}, \mathrm{PA}^{-}\right)$} & $\mathrm{O}-\mathrm{O}$ & 0 & 220 \\
\hline & $0-0-\pi$ & 14 & 265 \\
\hline & $0-\pi$ & 36 & 507 \\
\hline \multirow{3}{*}{$\left(\mathrm{Rb}^{+}, \mathrm{PA}^{-}\right)$} & $\mathrm{O}-\mathrm{O}$ & 0 & 218 \\
\hline & $0-0-\pi$ & 12 & 260 \\
\hline & $0-\pi$ & 34 & 499 \\
\hline \multirow{3}{*}{$\left(\mathrm{Cs}^{+}, \mathrm{PA}^{-}\right)$} & $\mathrm{O}-\mathrm{O}$ & 0 & 219 \\
\hline & $0-0-\pi$ & 7 & 257 \\
\hline & $0-\pi$ & 29 & 492 \\
\hline
\end{tabular}

Table 1. Gibbs relative energy $(\Delta G)$ and harmonic frequency splitting of the carboxylate stretching modes $\left(\Delta v\left(\mathrm{CO}_{2}^{-}\right)\right)$of the main conformers of $\left(\mathrm{M}^{+}, \mathrm{PA}^{-}\right)$for $\mathrm{M}=\mathrm{Li}-\mathrm{Cs}$ found at the RIB97-D3/dhf-TZVPP level.

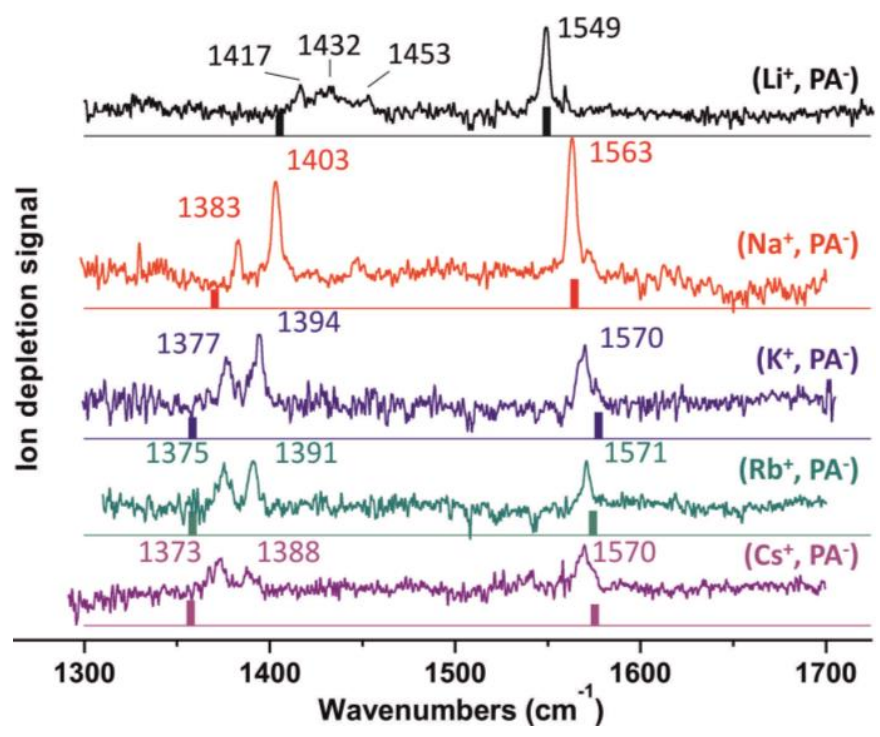

Figure 2. IR ion-depletion spectra of $\left(\mathrm{M}^{+}, \mathrm{PA}^{-}\right)$isolated ion pairs for $\mathrm{M}=\mathrm{Li}-\mathrm{Cs}$ in the spectral region of the $\mathrm{CO}_{2}^{-}$stretching modes. Mode-dependent scaled harmonic frequencies built with the scaling functions of Fig. 3 (Table S3) are also shown (bars).

Conformer-selective IR spectra were recorded for the five ion pairs considered (Fig. 2) and revealed the presence of only one conformer for each system. All IR spectra had a single transition in the $1540-1580 \mathrm{~cm}^{-1}$ range corresponding to $\left(\mathrm{CO}_{2}{ }^{-}\right)^{\text {anti }}$, and multiplets in the $1370-1460 \mathrm{~cm}^{-1}$ range, resulting from vibrational couplings of $\left(\mathrm{CO}_{2}^{-}\right)^{\text {sym }}$ with other modes, as 
previously observed for $\left(\mathrm{Li}^{+}, \mathrm{PA}^{-}\right) .{ }^{8}$ The frequency splitting of the $\mathrm{CO}_{2}^{-}$stretching modes is a clear-cut criterion confirming the assignment to $\mathrm{O}-\mathrm{O}$ conformers rather than to $\mathrm{O}-\pi$ conformers (Table 1 ). Firstly, the value for conformers $0-\pi$ is too large $\left(\sim 500 \mathrm{~cm}^{-1}\right)$ to fit the experimental data (115$190 \mathrm{~cm}^{-1}$ range) whereas that for O-O is in agreement (150$220 \mathrm{~cm}^{-1}$ range). Secondly, the experimental splitting increases when going down the group of alkali atoms, matching the behaviour predicted for $\mathrm{O}-\mathrm{O}$ conformers, but not that of $\mathrm{O}-\pi$ conformers.

\section{Beyond gas phase studies}

This dataset on $\left(\mathrm{M}^{+}, \mathrm{PA}^{-}\right)$isolated ion pairs provides an unprecedented benchmark for contact ion pairs between carboxylate groups and alkali cations paired in a bidentate manner. Taken in conjunction with published works on other carboxylate-containing systems in the gas phase, ${ }^{8-16}$ these results enable us (i) to evaluate how the vibrational probe (i.e. the carboxylate group) responds to a variety of environments, going from vacuum to doubly charged cations, and from bidentate to monodentate structures, and (ii) to assess the ability of the theoretical approach to quantitatively predict vibrational frequencies (Fig. 3, Tables S2 and S3). Firstly, correlation between experimental and theoretical harmonic frequencies is good for $\left(\mathrm{CO}_{2}^{-}\right)^{\text {sym }}$ and excellent for $\left(\mathrm{CO}_{2}^{-}\right)^{\text {anti }}$ (standard deviations are 15 and $5 \mathrm{~cm}^{-1}$ respectively), providing that each mode is considered separately. Secondly, to take advantage of such a good correlation in future calculations, harmonic frequencies must be scaled. To this end, a linear scaling function was determined for each mode. Such an empirical adjustment seeks to correct not only anharmonic effects, but also any systematic error of the method and the basis set, and has already proven considerable prediction capability, especially for non- or weakly coupled vibrational modes. ${ }^{44-46} \mathrm{~A}$ first outcome of these gas phase studies was thus to provide a theoretical approach based on modedependent scaled harmonic frequencies at the RI-B97-D3/dhfTZVPP level which can be used to investigate other systems, such as larger clusters or solution, with the preeminent advantage of knowing the accuracy of the calculation.

Another advantage of such gas phase studies is the isolation and unique documentation of individual species that are usually encountered in solution. Although direct comparison between gas phase and solution phase spectra is insubstantial, the information learned from gas phase isolated pairs is nonetheless useful for interpretation of solution phase data. Given the quasi-planarity of the $\mathrm{CO}_{2}^{-} \mathrm{M}^{+}$part of $\left(\mathrm{M}^{+}, \mathrm{PA}^{-}\right)$for $\mathrm{Li}$ and $\mathrm{Na}$ (Fig. S5), these systems can be considered as reasonable models of bidentate pairs between carboxylate and alkali cations. The spectral shifts observed along this series (Fig. 2) reveal the intrinsic response of carboxylate when immersed in the electric field of these cations in the gas phase. In solution, however, interpretation of spectral shifts along a series is made much more difficult due to other effects (differential solvation, type of pairing). In the context where gas phase benchmarks are now available, we carried out a critical analysis of recent results on pairing between acetate and sodium ions, ${ }^{5}$ and conclude that alternative interpretations of IR spectra in solution should be considered. This motivated us to perform a theoretical study able to produce vibrational spectra for each type of pair with the hope of suitably addressing assignment issues.

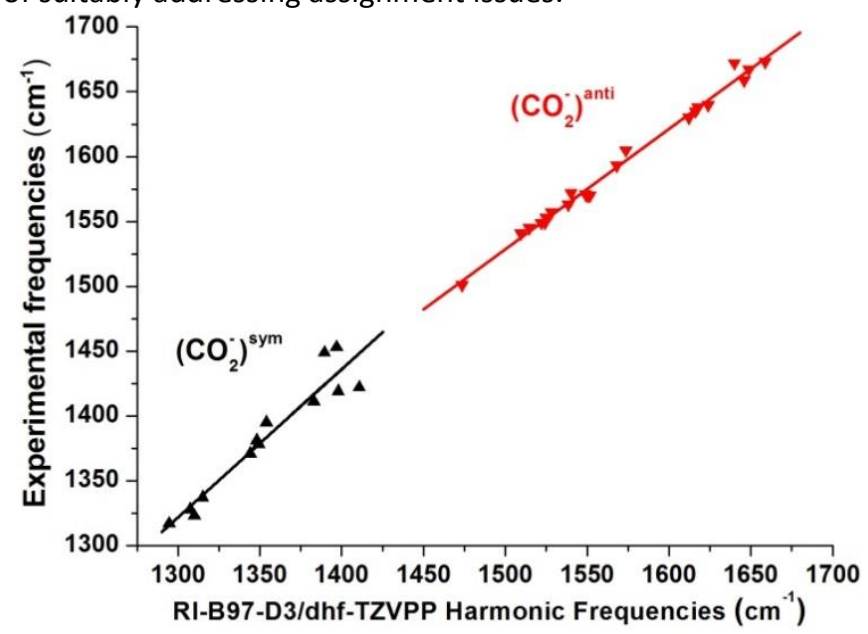

Figure 3. Experimental frequencies plotted against RI-B97D3/dhf-TZVPP harmonic frequencies $\left(f_{0}^{\text {th }}\right)$ (Table S2) for a set of carboxylate-containing systems in the gas phase ${ }^{8-16,}$ this work (triangles). An empirical scaling function is deduced for each $\mathrm{CO}_{2}^{-}$stretching mode by linear fitting (lines): $f^{\text {th }}=1.1431^{*} f_{0}{ }^{\text {th }}$ $164.3 \mathrm{~cm}^{-1}$ and $f^{t h}=0.9272{ }^{*} f_{0}{ }^{t h}+137.9 \mathrm{~cm}^{-1}$ for the symmetric (black) and antisymmetric (red) stretch respectively, where $f^{\text {th }}$ is the mode-dependent scaled frequency.

\section{IR spectra in solution}

Free acetate ions. The conformational search for acetatecontaining water aggregates (see section Methods) produced a large variety of structures which lead us to sort them in order to better rationalise their vibrational spectroscopy. The vibrational probe (i.e. the stretching modes of the carboxylate group) responds primarily to its immediate environment, so the structures were classified according to the coordination number of each oxygen atom of the carboxylate group, noted $\mathbf{n}$ and $\mathbf{m}$ respectively. The set of structures sharing the same coordination is noted $(\mathrm{n} \mid \mathrm{m})$, or $(\mathrm{n}[\mathrm{s}] \mathrm{m})$ when $\mathrm{s}$ ligands belong to the first solvation shell of both oxygen atoms. The most frequently found low energy structures belong either to $(3 \mid 3)$ $(47 \%)$, or (3|2) $(45 \%)$ types (Figure 4 , top structures). Very few $(8 \%)$ structures of other types, such as $(2 \mid 2),(4 \mid 3),(4 \mid 2),(3 \mid 1)$ or (4[1]3), were found; they were not subsequently considered. Sampling of the two main types was then carried out: sixteen structures were selected for geometry optimisation and frequency calculations to account for the diversity of structures found in the exploration, although one has to keep in mind that the parameters and the level of theory employed for the conformational search is not expected to provide quantitative ion pair type distributions. Results are presented in Tables 2 and S4.

Types (3|3) and (3|2) have quite different spectral signatures. The frequency splitting of the $\mathrm{CO}_{2}{ }^{-}$stretching modes of $(3 \mid 3)$ is 
smaller than that of $(3 \mid 2)$. A relatively small splitting is indeed expected when the carboxylate group is invested in a symmetric environment (equivalent $\mathrm{CO}$ bonds), whereas an asymmetric case would lead to a more pronounced single or double bond character of the $\mathrm{CO}$ bonds, and thus to a larger splitting. Considering the type distribution provided by the conformational search, $v\left(\mathrm{CO}_{2}^{-}\right)^{\text {sym }}$ and $v\left(\mathrm{CO}_{2}^{-}\right)^{\text {anti }}$ of free acetate ions are predicted at 1427 and $1562 \mathrm{~cm}^{-1}$, respectively. Given the error expected for this approach (15 and $5 \mathrm{~cm}^{-1}$ respectively) and the qualitative nature of the theoretical ion pair type distribution (see above), these theoretical frequencies agree quite well with the values reported for a dilute sodium acetate solution $\left(1413,5\right.$ and $\left.1556 \mathrm{~cm}^{-1}\right) .5$ Theoretical intensities and widths $(\sigma)$ of the transitions compare reasonably well to the experiment, although underestimations of the width and relative intensity of the antisymmetric transition were noted. Keeping in mind that other modes of smaller intensity are active in this spectral region, and that temperature effects are not taken into account by this theoretical approach, the overall agreement between the experimental and theoretical dataset at low concentration is satisfying.

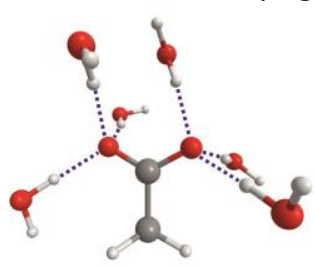

$(3 \mid 3)$

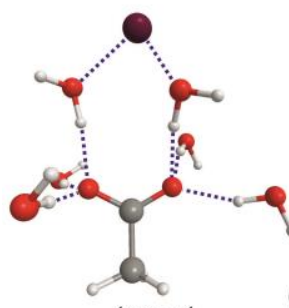

${ }^{1}(3 \mid 3)^{1}$

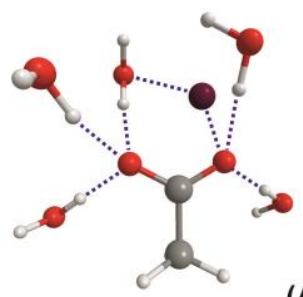

(3) 3$)$

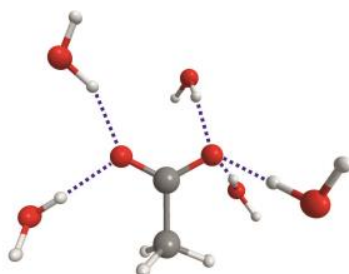

$(3 \mid 2)$

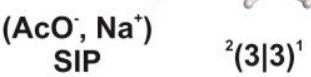

${ }^{2}(3 \mid 3)^{1}$

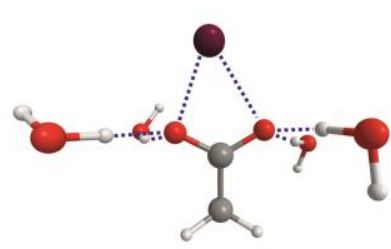

$\left(\mathrm{AcO} ; \mathrm{Na}^{+}\right)$ CIP
(3[1]3)
Figure 4. View of the acetate anion surrounded by its first solvation shell and the sodium cation, extracted from larger clusters optimised at the RI-B97-D3/dhf-TZVPP level. The type to which each structure belongs is also specified (see sections Free acetate ions and Sodium acetate ion pairs for type nomenclature).

Sodium acetate ion pairs. CIP and SIP structures were organized according to a nomenclature based on that of the free acetate ions. For CIPs, $(\underline{n} \mid m)$ is used for structures where the cation is among the $\mathbf{n}$ ligands; for SIPs, $a(n \mid m)^{b}$ is used for structures where $\mathbf{a}$ of the $\mathbf{n}$ (resp. $\mathbf{b}$ of the $\mathbf{m}$ ) water molecules belong to the first solvation shell of the cation (Fig. 4). Vibrational frequency changes induced by ion pairing can be seen in Table 2 where the most frequently found structures are reported (see also Table S4). Several trends can be observed, providing that $(3 \mid 3)$ and $(3 \mid 2)$ structures are considered separately.

\begin{tabular}{|c|c|c|c|c|}
\hline & type & $\begin{array}{c}v\left(\mathrm{CO}_{2}^{-}\right)^{\text {sym }} \\
(\sigma) \\
\mathrm{cm}^{-1} \\
\end{array}$ & $\begin{array}{c}v\left(\mathrm{CO}_{2}\right)^{-a n t i} \\
(\sigma) \\
\mathrm{cm}^{-1} \\
\end{array}$ & $\begin{array}{l}\text { I(sym)/ } \\
\text { I(anti) }\end{array}$ \\
\hline \multirow{3}{*}{$\mathrm{AcO}^{-}$} & $(3 \mid 3)$ & $1432(3)$ & 1559 (3) & $10 / 24$ \\
\hline & $(3 \mid 2)$ & $1420(11)$ & $1566(6)$ & $10 / 25$ \\
\hline & all & $1427(10)$ & $1562(5)$ & $10 / 25$ \\
\hline$\left(\mathrm{AcO}^{-}, \mathrm{Na}^{+}\right)$ & $\begin{array}{c}\text { dilute } \\
\text { solution }^{5}\end{array}$ & 1413.5 (11) & 1556 (17) & $10 / 34$ \\
\hline \multirow{5}{*}{$\begin{array}{c}\left(\mathrm{AcO}^{-}, \mathrm{Na}^{+}\right) \\
\text {SIP }\end{array}$} & ${ }^{1}(3 \mid 3)^{0}$ & $1426(5)$ & 1554 (9) & $10 / 28$ \\
\hline & ${ }^{1}(3 \mid 3)^{1}$ & $1429(8)$ & $1554(4)$ & $10 / 30$ \\
\hline & ${ }^{2}(3 \mid 3)^{1}$ & $1427(10)$ & $1548(3)$ & $10 / 26$ \\
\hline & ${ }^{1}(3 \mid 2)^{0}$ & $1421(10)$ & $1565(3)$ & $10 / 30$ \\
\hline & ${ }^{0}(3 \mid 2)^{1}$ & 1415 (7) & 1564 (9) & $10 / 34$ \\
\hline \multirow{4}{*}{$\begin{array}{c}\left(\mathrm{AcO}^{-}, \mathrm{Na}^{+}\right) \\
\mathrm{CIP}\end{array}$} & $(\underline{3} \mid 3)$ & $1427(10)$ & $1553(6)$ & $10 / 30$ \\
\hline & (3[1] 3$)$ & $1425(11)$ & $1554(6)$ & $10 / 35$ \\
\hline & $(\underline{3} \mid 2)$ & $1429(7)$ & $1568(10)$ & $10 / 30$ \\
\hline & $(3 \mid \underline{2})$ & $1416(8)$ & $1573(14)$ & $10 / 24$ \\
\hline
\end{tabular}

Table 2. Mode-dependent scaled harmonic frequencies $(v)$, standard deviations $(\sigma)$ and intensities (I) of the carboxylate stretching modes of free acetate ions and of its pairs with sodium cations in aqueous solution, compared to experimental data $^{5}$ (bold) recorded for a dilute solution. Standard deviations $(\sigma)$ are given for each set. Relative intensities are also reported with an intensity arbitrarily set at 10 for the symmetric stretch transitions. See text for type nomenclature.

By comparing $(3 \mid 3)$ frequencies with that of ${ }^{1}(3 \mid 3)^{0}, 1(3 \mid 3)^{1}$ and ${ }^{2}(3 \mid 3)^{1}$, one observes that SIP formation from free ions is accompanied by a red-shift of $v\left(\mathrm{CO}_{2}^{-}\right)^{\text {anti }}$ of 5 to $9 \mathrm{~cm}^{-1}$, which is larger than the accuracy of $v\left(\mathrm{CO}_{2}^{-}\right)^{\text {anti }}$ calculations $\left(5 \mathrm{~cm}^{-1}\right.$, see above). A red-shift of 3 to $6 \mathrm{~cm}^{-1}$ of $\mathrm{v}\left(\mathrm{CO}_{2}^{-}\right)^{\text {sym }}$ is also predicted, but is smaller than the expected accuracy for a calculation of this mode $\left(15 \mathrm{~cm}^{-1}\right)$. Moreover, $(3 \mid 2),{ }^{1}(3 \mid 2)^{0}$ and ${ }^{0}(3 \mid 2)^{1}$ structures have almost the same frequencies, $v\left(\mathrm{CO}_{2}^{-}\right)^{\text {sym }}$ of ${ }^{0}(3 \mid 2)^{1}$ being the only noticeable exception. IR spectroscopy may thus not be very sensitive to SIP formation from (3|2) structures. All together, these results show that SIP formation from free ions should result in a measurable red-shift of a few $\mathrm{cm}^{-1}$ of $v\left(\mathrm{CO}_{2}^{-}\right)^{\text {anti, }}$, mainly resulting from the pairing of $(3 \mid 3)$ structures.

Then, regarding the formation of CIPs from SIPs, the frequencies of ${ }^{1}(3 \mid 3)^{0}$ and ${ }^{1}(3 \mid 3)^{1}$ on one side, and $(\underline{3} \mid 3)$ and (3[1] 3 ) on the other side, are quite similar, making all these species potentially indistinguishable by IR spectroscopy. However, if $\operatorname{SIPS}^{1}(3 \mid 2)^{0}$ and ${ }^{0}(3 \mid 2)^{1}$ are compared to $\operatorname{CIPs}(\underline{3} \mid 2)$ and $(3 \mid \underline{2})$, one can see that a blue-shift up to $9 \mathrm{~cm}^{-1}$ of $v\left(\mathrm{CO}_{2}{ }^{-}\right)^{\text {anti }}$ is expected during CIP formation.

In conclusion, this theoretical study show that $\mathrm{CO}_{2}^{-}$stretch frequencies can be sensitive to both SIP and CIP formation, 
and that measurements of spectral shifts can document supramolecular structures in solution.

Experimental spectra. On the one hand, the novel theoretical approach presented in this article provides absolute vibrational frequencies that are consistent with those of dilute sodium acetate solutions; ${ }^{5}$ On the other hand, however, it associates ion pair formation to spectral shifts that have not been previously observed in the $0.03-2.2 \mathrm{M}$ concentration range. ${ }^{5}$ At $2.2 \mathrm{M}$, the number of water molecules available per sodium acetate entity is 23 , and is comparable to the number of water molecules needed to complete a first solvation shell around each ion ( 15 and $\sim 6$ water molecules for acetate and sodium ions respectively). $\sim 2.2 \mathrm{M}$ is thus the minimum concentration which ensures the presence of SIP in solution, but no data for the antisymmetric transition at higher concentrations are currently available, to the best of our knowledge. Additional FTIR spectra of sodium acetate solutions of increasing concentrations were recorded from 0.15 to $3.6 \mathrm{M}$ (Fig. 5). This new set of spectra does show a red-shift of the $\left(\mathrm{CO}_{2}^{-}\right)^{\text {anti }}$ transition of a few $\mathrm{cm}^{-1}$ starting at concentrations as low as $0.3 \mathrm{M}$ up to $3.6 \mathrm{M}$ (Fig. 6). In addition, a red-shift of the $\left(\mathrm{CO}_{2}^{-}\right)^{\text {sym }}$ transition is also observed together with an increase of the FHWM of both $\left(\mathrm{CO}_{2}^{-}\right)^{\text {sym }}$ and $\left(\mathrm{CO}_{2}^{-}\right)^{\text {anti }}$ transitions. These observations combined with the present simulations can then be used to document the supramolecular structures in solution.

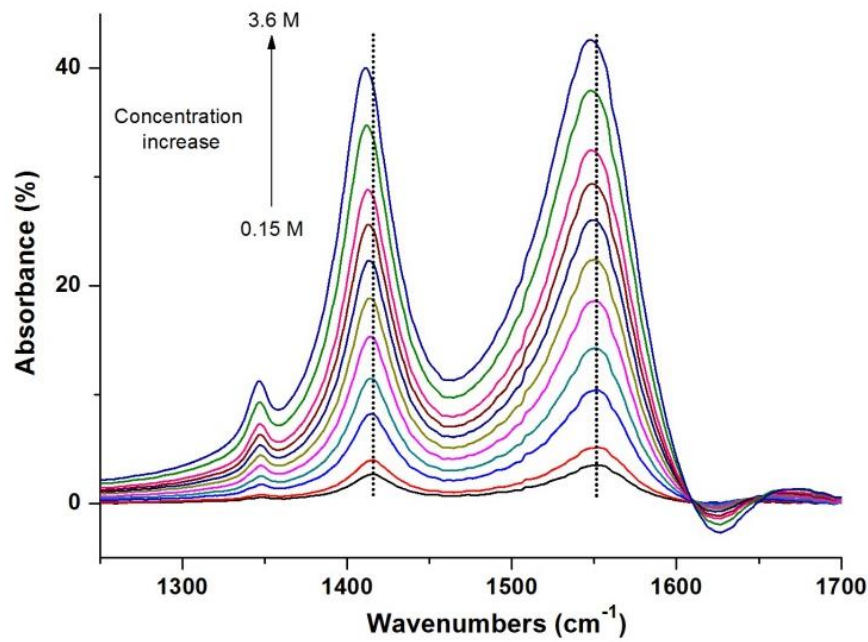

Figure 5. FTIR spectra of sodium acetate solutions of increasing concentration: $0.15,0.3,0.6,0.9,1.2,1.5,1.8,2.1,2.4,3.0$ and $3.6 \mathrm{M}$. Dashed lines mark the maximum of the $\left(\mathrm{CO}_{2}^{-}\right)^{\mathrm{sym}}$ and $\left(\mathrm{CO}_{2}{ }^{-}\right)^{\text {anti }}$ transitions at $0.15 \mathrm{M}$, highlighting the red-shift of these transitions at higher concentrations.

First, the increase of FHWM reveals the increasing diversity of structures in which the carboxylate is engaged, and is thus consistent with ion pair formation. According to our theoretical study, the red-shift of the $\left(\mathrm{CO}_{2}^{-}\right)^{\text {anti }}$ transition at low concentration can be assigned to the formation of SIPs such as ${ }^{1}(3 \mid 3)^{0},{ }^{1}(3 \mid 3)^{1}$ or ${ }^{2}(3 \mid 3)^{1}$. The red-shift of the $\left.\left(\mathrm{CO}_{2}\right)^{-}\right)^{\text {sym }}$ transition is also consistent with the formation of these species, as suggested by calculations (Table 2). As concentration is increased up to $3 \mathrm{M}$, where CIPs must be formed according to the number of water molecules left per sodium acetate entity, the $\mathrm{CO}_{2}{ }^{-}$stretch transitions still red-shift (Fig. 6), but a change of slope can be seen for $v\left(\mathrm{CO}_{2}^{-}\right)^{\text {anti }}$ around $2 \mathrm{M}$. The relatively smaller rate of red-shift above $2 \mathrm{M}$ may indicate the appearance of new species with a blue-shifted $\left.v\left(\mathrm{CO}_{2}\right)^{-}\right)^{\text {anti: }}$ this slowdown in red-shift could then result from an on-going population increase of species inducing a red-shift of the $\left(\mathrm{CO}_{2}^{-}\right)^{-}$anti transition, such as ${ }^{1}(3 \mid 3)^{0},{ }^{1}(3 \mid 3)^{1},{ }^{2}(3 \mid 3)^{1}$ SIPs, or $(\underline{3} \mid 3), \quad(3[\underline{1}] 3)$ CIPs coupled to the appearance of species inducing a blue-shift, such as ( $\underline{3} \mid 2)$ or (3| $)$ ) CIPs. Consequently, the change of slope at $\sim 2 \mathrm{M}$ could mark the concentration threshold for CIP appearance. Above $\sim 3 \mathrm{M}$, there are not enough water molecules to complete the first solvation shell around the most compact CIP. Ionic clusters larger than ion pairs are thus expected to contribute to the IR spectrum, but have not been investigated.

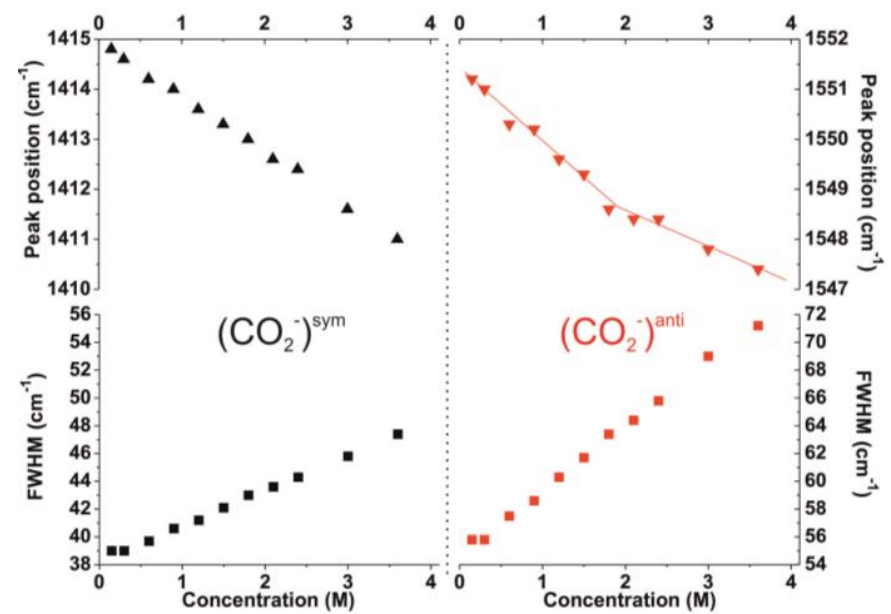

Figure 6. Peak position and full width at half maximum (FWHM) of the $\left(\mathrm{CO}_{2}^{-}\right)^{\text {sym }}$ (black) and $\left(\mathrm{CO}_{2}^{-}\right)^{\text {anti }}$ (red) transitions of FTIR spectra of Fig. 5 as a function of concentration.

An estimation of the ion pair type distribution was done previously by molecular simulations at the classical force field level, ${ }^{30}$ which predicted a significant contribution (33\%) of SIPs to the total acetate distribution at $1 \mathrm{M}$. These values support that enough SIP can be formed to be detected below $1 \mathrm{M}$, although these theoretical ion pair type distributions might be only qualitative due to the use of a non-polarisable force field. ${ }^{30}$

The FTIR spectra of the present work, however, differs significantly from previous similar experiments on both absolute frequencies, spectral shifts and $\mathrm{FWHM}$ of the $\mathrm{CO}_{2}^{-}$ stretch transitions: ${ }^{5}$ (i) free acetate transitions were observed at 1413.5 and $1556 \mathrm{~cm}^{-1}$, vs. 1415 and $1551 \mathrm{~cm}^{-1}$ in this work, (ii) observation of a $1.5 \mathrm{~cm}^{-1}$ blue-shift of $\mathrm{v}\left(\mathrm{CO}_{2}^{-}\right)^{\text {sym }}$ between 0 and $5 \mathrm{M}$, vs. $4 \mathrm{~cm}^{-1}$ red-shift between 0.15 and $3.6 \mathrm{M}$, (iii) 24 vs. $39 \mathrm{~cm}^{-1}$ for the symmetric transition of free acetate. This disparity may be ascribed to the differences between the operating conditions. In particular, solutions were investigated in this work at the surface of a synthetic diamond using the attenuated total reflection (ATR) technique, whereas Rudolph et al. ${ }^{5}$ studied solutions of capillary thickness between $\mathrm{AgCl}$ disks. In light of recent investigations pointing out the role 
interfaces on ion pairing, 51,52 it is legitimate to believe that these latter experimental conditions may particularly favour ion pairing/clustering at the surface of $\mathrm{AgCl}$ windows, which might explain the difference between both sets of experiments.

\section{Conclusions}

In this work, IR spectra of isolated ion pairs between phenylacetate and alkali cations (Li-CS) were recorded, and revealed the vibrational signature of carboxylate groups paired with alkali cations. Thanks to this unique dataset and other previous gas phase works, an original theoretical approach was designed to provide the vibrational signature of free acetate ions and its pairs with sodium ions in solution. In addition to provide theoretical spectra of free acetate ions in quantitative agreement with experimental spectra of dilute sodium acetate solution, this theoretical study found that ion pair formation should result in spectral shifts of the $\mathrm{CO}_{2}{ }^{-}$stretching modes depending on the type of ion pair formed. Such shifts were indeed observed by FTIR spectra in solution, demonstrating the sensitivity of this technique to ion pair formation. Specific SIPs and CIPs consistent with the observed spectral shifts were identified, and are thus likely to play a prominent role in ion pairing between sodium and acetate. Collectively, these results illustrate how accurate experimental gas phase data combined with a quantitative theoretical approach in solution provide invaluable benchmark data that can be used to investigate supramolecular structures in electrolyte solutions.

\section{Conflicts of interest}

There are no conflicts of interest to declare.

\section{Acknowledgements}

EG would like to acknowledge the work of undergraduate students A. Ghandri, S. Goursaud, S. Bourg and S. de LimaBarbosa. EG gratefully thank ANR (grant ANR-16-CE29-0017), GENCI-TGCC (projects t2016087524-A0010807524A0030807524 and p615) and LabEx PALM (ANR-10-LABX-0039PALM) for their support.

\section{References}

1. Y. Marcus and G. Hefter, Chem. Rev., 2006, 106, 4585.

2. N. F. A. van der Vegt, K. Haldrup, S. Roke, J. R. Zheng, M. Lund and H. J. Bakker, Chem. Rev., 2016, 116, 7626.

3. G. Hefter, Pure Appl. Chem., 2006, 78, 1571.

4. P. Jungwirth, J. Phys. Chem. B, 2014, 118, 10333.

5. W. W. Rudolph, D. Fischer and G. Irmer, Dalton Transactions, 2014, 43, 3174.

6. W. W. Rudolph and G. Irmer, RSC Adv., 2015, 5, 21897.

7. R. Cooper, A. M. Zolot, J. A. Boatz, D. P. Sporleder and J. A. Stearns, J. Phys. Chem. A, 2013, 117, 12419.

8. S. Habka, V. Brenner, M. Mons and E. Gloaguen, J. Phys. Chem. Lett., 2016, 7, 1192.
9. C. Kapota, J. Lemaire, P. Maitre and G. Ohanessian, J. Am. Chem. Soc., 2004, 126, 1836.

10. R. C. Dunbar, N. C. Polfer and J. Oomens, J. Am. Chem. Soc., 2007, 129, 14562.

11. M. F. Bush, J. Oomens, R. J. Saykally and E. R. Williams, J. Am. Chem. Soc., 2008, 130, 6463.

12. R. C. Dunbar, A. C. Hopkinson, J. Oomens, C. K. Siu, K. W. M. Siu, J. D. Steill, U. H. Verkerk and J. F. Zhao, J. Phys. Chem. B, 2009, 113, 10403.

13. J. Oomens, J. D. Steill and B. Redlich, J. Am. Chem. Soc., 2009, 131,4310 .

14. M. K. Drayss, D. Blunk, J. Oomens, B. Gao, T. Wyttenbach, M. T. Bowers and M. Schafer, J. Phys. Chem. A, 2009, 113, 9543.

15. R. C. Dunbar, J. D. Steill and J. Oomens, Phys. Chem. Chem. Phys., 2010, 12, 13383.

16. M. K. Drayss, P. B. Armentrout, J. Oomens and M. Schaefer, Int. J. Mass Spectrom., 2010, 297, 18.

17. R. C. Dunbar, in Gas-Phase IR Spectroscopy and Structure of Biological Molecules, eds. A. M. Rijs and J. Oomens, SpringerVerlag Berlin, Berlin, 2015, vol. 364, pp. 183.

18. W. J. Zhang, G. L. Hou, P. Wang, H. G. Xu, G. Feng, X. L. Xu and W. J. Zheng, J. Chem. Phys., 2015, 143.

19. G. L. Hou, C. W. Liu, R. Z. Li, H. G. Xu, Y. Q. Gao and W. J. Zheng, J. Phys. Chem. Lett., 2017, 8, 13.

20. J. W. DePalma, P. J. Kelleher, L. C. Tavares and M. A. Johnson, J. Phys. Chem. Lett., 2017, 8, 484.

21. A. M. Sadoon, G. Sarma, E. M. Cunningham, J. Tandy, M. W. D. Hanson-Heine, N. A. Besley, S. F. Yang and A. M. Ellis, J. Phys. Chem. A, 2016, 120, 8085.

22. J. Tandy, C. Feng, A. Boatwright, G. Sarma, A. M. Sadoon, A. Shirley, N. D. Rodrigues, E. M. Cunningham, S. F. Yang and A. M. Ellis, J. Chem. Phys., 2016, 144.

23. D. Strasser, F. Goulay, M. S. Kelkar, E. J. Maginn and S. R. Leone, J. Phys. Chem. A, 2007, 111, 3191.

24. E. I. Obi, C. M. Leavitt, P. L. Raston, C. P. Moradi, S. D. Flynn, G. L. Vaghjiani, J. A. Boatz, S. D. Chambreau and G. E. Douberly, J. Phys. Chem. A, 2013, 117, 9047.

25. M. J. Earle, J. Esperanca, M. A. Gilea, J. N. C. Lopes, L. P. N. Rebelo, J. W. Magee, K. R. Seddon and J. A. Widegren, Nature, 2006, 439, 831.

26. M. Nara, H. Torii and M. Tasumi, J. Phys. Chem., 1996, 100, 19812.

27. K. D. Collins, Biophys. Chem., 2006, 119, 271.

28. K. D. Collins, Biophys. Chem., 2012, 167, 43.

29. P. Lo Nostro and B. W. Ninham, Chem. Rev., 2012, 112, 2286

30. B. Hess and N. F. A. van der Vegt, Proc. Natl. Acad. Sci. U. S. A., 2009, 106, 13296.

31. H. M. A. Rahman and R. Buchner, Journal of Molecular Liquids, 2012, 176, 93.

32. H. M. A. Rahman, G. Hefter and R. Buchner, J. Phys. Chem. B, 2012, 116, 314

33. E. F. Aziz, N. Ottosson, S. Eisebitt, W. Eberhardt, B. JagodaCwiklik, R. Vacha, P. Jungwirth and B. Winter, J. Phys. Chem. B, 2008, 112, 12567

34. J. S. Uejio, C. P. Schwartz, A. M. Duffin, W. S. Drisdell, R. C. Cohen and R. J. Saykally, Proc. Natl. Acad. Sci. U. S. A., 2008, 105, 6809 .

35. E. Gloaguen, H. Valdes, F. Pagliarulo, R. Pollet, B. Tardivel, P. Hobza, F. Piuzzi and M. Mons, J. Phys. Chem. A, 2010, 114, 2973.

36. R. H. Page, Y. R. Shen and Y. T. Lee, J. Chem. Phys., 1988, 88, 4621. 
37. S. Grimme, J. Antony, S. Ehrlich and H. Krieg, J. Chem. Phys., 2010, 132, 19.

38. A. Schäfer, C. Huber and R. Ahlrichs, J. Chem. Phys., 1994, 100, 5829.

39. F. Weigend, M. Häser, H. Patzelt and R. Ahlrichs, Chem. Phys. Lett., 1998, 294, 143.

40. F. Weigend and A. Baldes, J. Chem. Phys., 2010, 133.

41. TURBOMOLE V7.0 2015, a development of University of Karlsruhe and Forschungszentrum Karlsruhe GmbH, 1989-2007, TURBOMOLE GmbH, since 2007; available from http://www.turbomole.com

42. S. F. Boys and F. Bernardi, Mol. Phys., 1970, 19, 553.

43. K. Raghavachari, G. W. Trucks, J. A. Pople and M. Headgordon, Chem. Phys. Lett., 1989, 157, 479.

44. H. S. Biswal, Y. Loquais, B. Tardivel, E. Gloaguen and M. Mons, J. Am. Chem. Soc., 2011, 133, 3931.

45. R. J. Plowright, E. Gloaguen and M. Mons, Chemphyschem, 2011, 12, 1889.

46. E. Gloaguen and M. Mons, in Gas-Phase IR Spectroscopy and Structure of Biological Molecules, eds. A. M. Rijs and J. Oomens, 2015, vol. 364, pp. 225.

47. M. L. Laury, L. P. Wang, V. S. Pande, T. Head-Gordon and J. W. Ponder, J. Phys. Chem. B, 2015, 119, 9423.

48. TINKER V7.1-2015, Software tools for molecular design, Jay Ponder Lab, Department of Chemistry, Washington University, Saint Louis, Missouri 63130 U.S.A.; available from http://dasher.wustl.edu/tinker/

49. L. Piela, J. Kostrowicki and H. A. Scheraga, J. Phys. Chem., 1989, 93, 3339.

50. A. Klamt and G. Schuurmann, J. Chem. Soc., Perkin Trans. 2, 1993, DOI: 10.1039/p29930000799, 799.

51. D. E. Otten, R. Onorato, R. Michaels, J. Goodknight and R. J. Saykally, Chem. Phys. Lett., 2012, 519-20, 45.

52. L. X. Dang, G. K. Schenter and C. D. Wick, Journal of Physical Chemistry C, 2017, 121, 10018. 